ARTIGOS

\title{
O observatório da educação (OBEDUC) e sua contribuição para a formação docente na UFPI
}

\begin{abstract}
RESUMO
Este artigo apresenta as contribuições do Programa Observatório da Educação (OBEDUC/CAPES) realizado pelo NIPEEPP/PPGEd, da Universidade Federal do Piauí para a formação docente. O desenvolvimento do projeto "A escola de tempo integral na perspectiva da educação integral: um estudo sobre a epistemologia escolar constituída pela gestão e organização do trabalho pedagógico", no âmbito do OBEDUC, fomentou a produção acadêmica sobre o tema, articulando a Pós-graduação, as licenciaturas e as escolas de educação básica envolvidas. Seus resultados incidem diretamente na formação de seus sujeitos, uma vez que a mesma é orientada pela pesquisa, pela prática, pela reflexão; portanto, mais sólida, crítica e reflexiva, fundada no compromisso, na autonomia e emancipação do sujeito. Nossa experiência e resultados mostram os impactos relevantes do OBEDUC para a educação e, principalmente, para a formação de professores. Por esta razão seria interessante que fosse mantido e ampliado CAPES, seja em forma de projetos individuais ou em rede.
\end{abstract}

PALAVRAS-CHAVE

OBEDUC; Formação Docente; Escola de Tempo Integral.

\begin{abstract}
This article presents the contributions of the Program Observatory of Education (OBEDUC/CAPES) conducted by NIPEEPP / PPGEd, University Piauí Federal for teacher training. The development of the project "The school full-time from the perspective of integral education: a study on school epistemology consisting of the management and organization of pedagogical work" under the OBEDUC, encouraged the academic research on the subject, linking the Graduate the degree and basic education schools involved. Its results have a direct impact on the formation of their subjects, since the same-driven research, practice, by reflection; therefore more solid, critical and reflective, based on commitment, autonomy and emancipation of the subject. Our experience and results show the significant impacts of OBEDUC for education and especially for the training of teachers. For this reason it would be interesting to be maintained and expanded CAPES, whether in the form of individual projects or network.
\end{abstract}

\section{KEYWORDS}

OBEDUC; Teacher training; Full Time School. 


\section{INTRODUÇÃO}

O Programa Observatório da Educação, financiado pela CAPES, foi aprovado pela Portaria CAPES n 152 , de 30 de outubro de 2012, o Decreto n 5.803, de 8 de junho de 2006 e a Lei n 9.784, de 29 de janeiro de 1999 com a intenção de apoiar o desenvolvimento de projetos de pesquisa em ensino e educação que utilizem as bases de dados do INEP. Teve como finalidade o fomento da produção acadêmica e a formação de recursos humanos em educação, em nível de pós-graduação, mestrado e doutorado, e incentivar a articulação entre pós-graduação, licenciaturas e escolas da rede pública de educação básica. No ano de 2012 , o Núcleo Interdisciplinar de Pesquisa em Educação e Epistemologia da Prática Profissional (NIPEEPP), vinculado ao Programa de Pós-Graduação em Educação (PPGEd) da Universidade Federal do Piauí, através Edital CAPES N 49/2012 pleiteou a aprovação do Projeto de pesquisa "A escola de tempo integral na perspectiva da educação integral: um estudo sobre a epistemologia escolar constituída pela gestão e organização do trabalho pedagógico", no âmbito do Programa Observatório da educação. O projeto foi desenvolvido entre os anos de 2013 e 2015, originando inúmeros resultados e contribuições para aqueles que participaram do OBEDUC.

A pesquisa teve como objetivo apresentar as contribuições do Observatório da Educação (OBEDUC) para a formação docente na UFPI. Para isso, buscamos caracterizar as atividades desenvolvidas pelo OBEDUC/ UFPI; compreender como se configura a gestão e organização do trabalho pedagógico nas escolas de tempo integral, da rede estadual de ensino, em Teresina. Caracterizou-se como um estudo sobre a epistemologia da vida escolar construída pela prática educativa cotidiana, inserindo-se, portanto, no campo das práticas educativas, uma das categorias fundamentais da atividade humana, concebida à base de racionalidades que dominam a nossa cultura (HABERMAS, 2002).

Também se insere no âmbito teórico recente, denominado de epistemologia da prática cuja finalidade é conhecer a natureza dos saberes profissionais, sua integração nas atividades do trabalho e o papel que desempenham neste processo (SCHÖN, 2000). O enfoque foi narrativo-interpretativo e estuda a voz dos atores escolares que são desprendidas por pensamentos e razões que não são restritas à subjetividade apenas, uma vez que eles são socialmente construídos (TARDIF, 2002).

Buscamos através da inserção no ambiente escolar, compreender a escola de tempo integral, bem como, seus sujeitos, seus espaços, seus saberes, seu tempo e seu modus operandi. Interessou-nos, portanto, entender este modelo de escola e sua epistemologia, ou seja, sua construção, gerada na interação de seus sujeitos, com sua natureza e seus problemas.

O estudo teve abordagem qualitativa de caráter etnometodológico (COULON, 1995), por ser característico de uma racionalidade oriunda das descrições reflexivas produzidas pelos membros da comunidade escolar. Os sujeitos foram os professores, diretores e coordenadores de duas escolas públicas de tempo integral da rede estadual de ensino, localizadas na zona leste da cidade de Teresina-PI. Sendo elas, o C.E.T.I. Professor Darcy Araújo e o C.E.T.I. Governador Freitas Neto.

As técnicas utilizados foram o questionário e a entrevista semiestruturados, a observação participante e o grupo focal. Observou-se que a realização deste estudo fomentou a produção acadêmica sobre o tema, articulando a interação entre a pós-graduação, as licenciaturas e as escolas da rede pública de educação básica.

Os resultados contribuíram para revitalizar e aprofundar as discussões acerca da formação para a integralidade humana, considerando o modelo de escola de tempo integral e poderão ser utilizados para a reflexão sobre a epistemologia da prática escolar no contexto da formação para a cidadania, colaborando com a ampliação do próprio campo de conhecimento em constituição. 


\section{autêntica}

\section{CAMINHO METODOLÓGICO}

Como a gestão e organização do trabalho pedagógico, explicitadas pelos sujeitos da escola sedimenta-se nas situações reais de sua prática, relacionado ao tipo de aluno que tem às condições e aos recursos institucionais, bem como as concepções que geram do trabalho educativo no modelo de escola de tempo integral (ANDRÉ, 1995), nos propormos a realizar uma pesquisa de abordagem qualitativa e caráter etnometodológico (COULON, 1995). Oferece condições de percebermos os significados expressos, seja pela verbalização dos sujeitos e/ou pelas suas ações possibilitando a análise do processo em que são evidenciados os saberes profissionais dos docentes, in loco.

As atividades do projeto foram iniciadas com a seleção dos bolsistas. A seleção ocorreu através de um edital específico, em que foram explicitados os princípios teórico-metodológicos do OBEDUC/UFPI e as condições do programa. Os bolsistas de mestrado foram aqueles que já haviam sido selecionados para o programa. Os professores colaboradores foram convidados considerando a mesma linha de pesquisa e o interesse pela temática.

Os bolsistas do OBEDUC assumiram como compromisso e atribuições: executar o plano de atividades elaborado no âmbito do projeto de pesquisa; apresentar formalmente os resultados parciais e finais de seu trabalho de pesquisa divulgando-os na instituição onde estuda, em eventos científico-acadêmicos; participar de atividades acadêmico-científico-culturais promovidas pelo OBEDUC; dedicar-se, no período de vigência da bolsa, 12 (doze) horas semanais, às atividades do OBEDUC sem prejuízo de suas atividades discentes regulares; manter atitudes de solidariedade, respeito e ética a toda a comunidade acadêmica e escolar e a equipe do grupo. Todos eles assinaram Termo de Compromisso obrigando-se a cumprir as metas pactuadas pela IES no projeto e a devolver à CAPES eventuais benefícios recebidos indevidamente.

Pensar em construir a interpretação de um fenômeno, sobremodo quando este se refere a questões concernentes na escola à gestão e organização do trabalho pedagógico na escola de tempo integral, como idealizamos, implica preocupar-se com a matriz paradigmática em que ele vai ser compreendido. Em vista disso, e pela impulsão da força determinante da racionalidade dialógico-comunicativa na apreensão das práticas sociais, usamos suas lentes sob o olhar da Teoria Crítica, para compreender a própria epistemologia da vida escolar, pelas vias de seus sujeitos.

Assim, realizamos diversos estudos teóricos, dos quais destacamos as obras de: Teixeira (1997; 1994), Morin (2007), Alarcão (2010), Amaral (2013), Gadotti (2009), Gonçalves (2006), Tardif (2002), dentre outros.

A pesquisa teve como lócus de investigação 2 (duas) escolas públicas estaduais, de Tempo Integral. A primeira sendo o C.E.T.I. Professor Darcy Araújo, situada na Av. Nossa Senhora de Fátima s/n, no bairro de Fátima, sendo uma escola de tempo integral que oferta o Ensino Fundamental do $4^{\circ}$ ao $9^{\circ}$ ano e Ensino Médio do $1^{\circ}$ ao $3^{\circ}$ ano. A segunda escola é o C.E.T.I. Governador Freitas Neto, localizada na Av. Capitão Wanderlei s/n, no bairro Piçarreira, e consiste também em uma escola de tempo integral, ofertando todo o Ensino Fundamental e o Ensino Médio. Ambas estão localizadas na cidade de Teresina-PI.

Efetuamos a observação do cotidiano da escola, com visitas as duas escolas pesquisadas. Além disso, utilizamos a análise documental, tanto pelo uso do Projeto Político Pedagógico da escola, como do banco de dados do Instituto Nacional de Estudos e Pesquisas Educacionais Anísio Teixeira (INEP), sejam referentes ao Censo Escolar, à Prova Brasil, ao Exame Nacional do Ensino Médio (ENEM), ao Índice de Desenvolvimento 


\section{DOCENTE}

autêntica

da Educação Básica (IDEB) o ao Programa Internacional de Avaliação de Estudantes (PISA), para subsidiar as discussões e análises da realidade educacional brasileira, especificamente a do Piauí, no que tange a educação básica. Seus desafios traduzem a compreensão do direito de aprender como inerente ao direito à vida, à saúde, à liberdade, ao respeito, à dignidade e à convivência familiar e comunitária e como condição para o próprio desenvolvimento de uma sociedade republicana e democrática. Por meio da Educação Integral, se reconhece as múltiplas dimensões do ser humano e a peculiaridade do desenvolvimento de crianças, adolescentes e jovens (BRASIL, 2014, p. 07-08).

Apresentamos a seguir, na Tabela 1, alguns dados obtidos nas visitas às escolas.

TABELA 1 - DADOS DO C.E.T.I. PROFESSOR DARCY ARAÚJO.

\begin{tabular}{c|c|c}
\hline \multirow{2}{*}{ CATEGORIAS } & \multicolumn{2}{c}{ QUANTIDADE } \\
\hline Alunos & CETI Darcy Araújo & CETI Governador Freitas \\
\hline Alunos especiais & 330 & 788 \\
\hline Professores & 04 & 19 \\
\hline Ensino fundamental menor & 21 & 47 \\
\hline Ensino fundamental maior & 03 Turmas & 11 Turmas \\
\hline \multirow{2}{*}{ Ensino médio } & 05 Turmas & 02 Turmas \\
\hline IDEB & 01 Turma do $1^{\circ}$ ano $1^{\circ}$ ano \\
\hline
\end{tabular}

Fonte: Dados Obeduc/UFPI, 2014.

Os sujeitos da pesquisa foram constituídos pelos professores, alunos, diretores e coordenador pedagógico das escolas conveniadas, onde trabalhamos colaborativamente com todos eles. Em principio, foram entrevistados professores, diretores e coordenadores. Em seguida, utilizamos os questionários (MOREIRA; CALEFFE, 2008), para uma melhor compreensão da constituição epistemológica do modelo de escola desenvolvido, além da entrevista semiestruturada, a observação participante e os grupos focais.

Estas técnicas permitiram identificar procedimentos e estratégias que eles usam para construir sua prática pedagógica e torná-la familiar e significativa, bem como a forma como planejam as atividades sóciointegradoras na escola de tempo integral e qual o sentido e a eficácia desta escola. Isso significa que, nossa interpretação fez-se a partir da análise da conversação proveniente da etnometodologia, cujo método documentário de interpretação permite retirar padrões de sentido para as falas dos sujeitos, ou seja, os temas, as categorias; porém, com o apoio da hermenêutica.

Nosso enfoque foi narrativo-interpretativo, baseado na voz dos atores escolares que são desprendidas por pensamentos e razões que não são restritas à subjetividade apenas, uma vez que eles são socialmente construídos. 


\section{autêntica}

\section{O CONTEXTO DO OBEDUC/UFPI}

O projeto desenvolvido pelo OBEDUC/UFPI foi desenvolvido no período de 2013 a 2015. Ao desenvolver o projeto, a equipe do OBEDUC integrou em 2013, três alunos bolsistas de mestrado; oito alunos dos cursos de licenciatura; três professores da educação básica; dois alunos bolsistas do PIBIC, que possuíam bolsas em nível de UFPI e de CNPq; uma aluna de Trabalho de Conclusão de Curso (TCC) e um professor colaborador que estiveram envolvidos na discussão acerca da educação integral, na constituição de competências e do papel da escola no século XXI, especificamente o modelo de escola de tempo integral e suas práticas educativas na perspectiva da formação da integralidade do educando.

Através do Edital 49/2012 OBEDUC/CAPES, financiou projetos que seriam realizados em redes e projetos locais, como foi o nosso caso. Apesar deste projeto ser caracterizado como local, o mesmo agregou mais dois projetos estudos no interior do NIPEPP/UFPI. O primeiro trata de uma investigação do "Plano Nacional de Formação dos Professores da Educação Básica e a constituição da epistemologia da prática docente: um estudo sobre a formação docente desenvolvida pela UFPI, no âmbito do PARFOR". O segundo, no campo do currículo intitulado de "A constituição do perfil dos profissionais da área médica: uma análise da racionalidade da dimensão didático-pedagógica do Curso de Medicina da UFPI". Ambos realizados no interior do Programa de Iniciação Científica (PIBIC). O valor financiado foi de $\mathrm{R} \$ 223.880,00$ (duzentos e vinte e três mil, oitocentos e oitenta reais). Destes $\mathrm{R} \$ 173.880,00$ (cento e setenta e três mil, oitocentos e oitenta reais) forma destinados ao pagamento de bolsas e $\mathrm{R} \$ 50.000,00$ (cinquenta mil) para custeio, conforme quadro abaixo:

FINANCIAMENTO OBEDUC/NIPEEPP/UFPI

\begin{tabular}{|c|c|c|c|}
\hline $\mathrm{R} \$ 173.880,00$ & $\mathrm{R} \$ 50.000,00$ & $\mathrm{R} \$ 50.000,00$ & $\mathrm{R} \$ 231.880,00$ \\
Bolsas & Custeio & Custeio & Total \\
\hline
\end{tabular}

Quadro 1 - Detalhamento do financiamento OBEDUC/NIPEEPP/UFPI.

Fonte: Projeto OBEDUC, 2014.

Considerando que um dos objetivos do Obeduc foi estimular o fortalecimento e a ampliação de programas de pós-graduação stricto sensu e de redes de pesquisa no país que tenham a educação como eixo de investigação; a UFPI, através do Programa de Pós-Graduação em Educação e do NIPEEPP, possibilitou o desenvolvimento de pesquisa acerca da educação, da escola de tempo integral, da formação de professores, do desenvolvimento profissional docente. Além disso, quando estudou a escola de tempo integral e estimulou o uso de dados estatísticos educacionais produzidos pelo INEP como subsídio ao aprofundamento de estudos sobre a realidade educacional brasileira, cumprindo, também, outros objetivos do programa e, por fim, ao divulgar a produção e os resultados encontrados, compartilhando conhecimento e boas práticas e integrando a pesquisa à dinâmica da Universidade e dos sistemas públicos de educação básica. A realização deste projeto nos possibilitou, ainda, a ampliação da produção científica, tecnológica e de informação sobre a escola de tempo integral na perspectiva da integralidade da formação humana.

Tais fatores caracterizam-na como inovadora e relevante. Ou seja, inovadora pela incipiência de estudos acerca do tema, no Piauí e relevante por acentuar a capacidade de ampliar a produção de conhecimento no 


\section{DOCENTE}

\section{autêntica}

interior de programas de pós-graduação, colaborando, sobremodo, para revitalizar e aprofundar as discussões acerca da formação para a integralidade humana, considerando o modelo de escola de tempo integral.

Ressalte-se que as temáticas discutidas, perpassaram a epistemologia da prática, pois implica na forma como o conhecimento é construído, seja na escola, seja na universidade. Uma vez que todos os participantes são ou estivaram vinculados ao NIPEPP, tendo sido acompanhados de maneira natural.

Dentre os cursos de licenciatura envolvidos no projeto, temos Pedagogia, História, Biologia, Matemática. Além de alunas do Mestrado em Educação, do PPGEd/UFPI.

TABELA 2 - BOLSISTAS QUE PERMANECERAM NO PROGRAMAS ATÉ INICIO/MEADOS DE 2014.

\begin{tabular}{c|c}
\hline FUNÇÃO NO PROJETO & No DE INTEGRANTES \\
\hline Bolsista do Obeduc/UFPI & 10 \\
\hline Orientanda de TCC & 1 \\
\hline Bolsista PIBIC & 2 \\
\hline Bolsista PIBID & 4 \\
\hline Bolsista PPGED/UFPI & 2 \\
\hline
\end{tabular}

Fonte: Dados Obeduc/UFPI, 2014.

Apresentamos a seguir, os resultados obtidos com o desenvolvimento deste projeto OBEDUC/UFPI, de grande contribuição para a sociedade acadêmica e comunidade educacional em geral.

\section{RESULTADOS ALCANÇADOS DO OBEDUC/UFPI}

\section{CONTRIBUIÇÕES PARA OS ALUNOS, PROFESSORES E PARA AS LICENCIATURAS DA IES,}

Na equipe do Projeto OBEDUC/UFPI, integrou vinte e um alunos. Estes apresentam avanços no desenvolvimento de competências e habilidades relativas ao desempenho acadêmico e este aspecto, traz melhorias às licenciaturas, ainda que de forma tímida. A contribuição maior vai incidir por ocasião da realização do nosso | Colóquio, que irá envolver as licenciaturas. Porém, na pós-graduação, os impactos são maiores, em razão dos três mestrandos bolsistas envolvidos ter dedicação exclusiva ao projeto e ao curso.

No Quadro 2, descrevemos algumas das principais atividades desenvolvidas pelo OBEDUC/UFPI no seu período de atuação. 


\section{autêntica}

\begin{tabular}{|c|c|c|c|}
\hline $\begin{array}{l}\text { INDICADOR } \\
\text { DA ATIVIDADE }\end{array}$ & $\begin{array}{l}\text { OBJETIVO DA } \\
\text { ATIVIDADE }\end{array}$ & $\begin{array}{l}\text { DESCRIÇÃO SUCINTA } \\
\text { DA ATIVIDADE (INSERIR } \\
\text { INÍCIO E PERIOODO DE } \\
\text { REALIZAÇÃO) }\end{array}$ & RESULTADOS ALCANÇADOS \\
\hline 1 & Apresentar do projeto. & $\begin{array}{l}\text { Leitura e discussão do } \\
\text { projeto de pesquisa, em } \\
\text { abril de } 2013 .\end{array}$ & $\begin{array}{l}\text { Compreensão do objeto de } \\
\text { estudo. }\end{array}$ \\
\hline 2 & $\begin{array}{l}\text { Estudar o referencial } \\
\text { teórico da pesquisa: } \\
\text { a.O manisfesto dos } \\
\text { pioneiros da educação; } \\
\text { b.Paulo Freire; } \\
\text { c. Edgar Morin; } \\
\text { d.Escola de Tempo } \\
\text { Integral } \\
\text { e.Habermas } \\
\text { f. Gadamer, dentre } \\
\text { outros. }\end{array}$ & $\begin{array}{l}\text { Estudos, individual e } \\
\text { em grupo, acerca do } \\
\text { referencial teórico da } \\
\text { pesquisa. } \\
\text { Todas as quintas-feiras, } \\
\text { a equipe se encontra, no } \\
\text { horário de } 15 \text { as } 18 \mathrm{~h}, \text { para } \\
\text { cumprir esta atividade. }\end{array}$ & $\begin{array}{l}\text { Compreensão do que seja } \\
\text { educação de tempo integal, } \\
\text { suas origens e defensores e } \\
\text { das teorias contemporâneas } \\
\text { que embasam a educação. }\end{array}$ \\
\hline 3 & $\begin{array}{c}\text { Produzir conhecimentos } \\
\text { e saberes sobre a } \\
\text { docência e a escola. }\end{array}$ & $\begin{array}{l}\text { Sistemação das leituras } \\
\text { e reflexões realizadas no } \\
\text { âmbito do núcleo. }\end{array}$ & $\begin{array}{c}\text { Publicação de artigos em } \\
\text { eventos. }\end{array}$ \\
\hline 4 & $\begin{array}{l}\text { Participar e apresentar } \\
\text { trabalhos em eventos }\end{array}$ & $\begin{array}{c}\text { Participação em } \\
\text { congressos da área de } \\
\text { educação. }\end{array}$ & $\begin{array}{c}\text { Particpação no EPENN, } \\
\text { AFIRSE, VIII Colóquio } \\
\text { Internacional de Educação e } \\
\text { Contemporaneidade }\end{array}$ \\
\hline 5 & $\begin{array}{c}\text { Aproximar os bolsistas } \\
\text { da graduação e da pós } \\
\text { do lócus de pesquisam } \\
\text { com a colaboração } \\
\text { dos professores, } \\
\text { coordenadores das } \\
\text { escolas. }\end{array}$ & $\begin{array}{l}\text { Visitas da equipe às duas } \\
\text { escolas pesquisadas, seis } \\
\text { participantes por escola. }\end{array}$ & $\begin{array}{c}\text { Produção de relatório e } \\
\text { apresentação em slides das } \\
\text { atividadee. } \\
\text { Troca de experiências e } \\
\text { informações. }\end{array}$ \\
\hline 6 & $\begin{array}{l}\text { Conhecer a teoria } \\
\text { sistêmica. }\end{array}$ & $\begin{array}{l}\text { Exibição do filme: Ponto de } \\
\text { Mutação, de Fritjof Capra. }\end{array}$ & $\begin{array}{l}\text { Compreensão da teoria } \\
\text { sistêmica. }\end{array}$ \\
\hline 7 & $\begin{array}{l}\text { Realizar pesquisa de } \\
\text { campo. }\end{array}$ & $\begin{array}{l}\text { Inserção da equipe nas } \\
\text { duas escolas, cada um } \\
\text { dos membros com tareda } \\
\text { delimitada para auscutar a } \\
\text { escola e seus atores. }\end{array}$ & Coleta de dados. \\
\hline 8 & $\begin{array}{l}\text { Organizar um encontro } \\
\text { do OBEDUC. }\end{array}$ & $\begin{array}{l}\text { Organização de um } \\
\text { encontro do NIPEEPP para } \\
\text { divulgação do OBEDUC. }\end{array}$ & $\begin{array}{l}\text { I Colóquio de Pesquisa, } \\
\text { Práticas e Aprendizagens na } \\
\text { Educação (I CPPAE/ UFPI) }\end{array}$ \\
\hline
\end{tabular}

Fonte: Dados OBEDUC/UFPI, 2015. 
As atividades destacam a vasta produção do conhecimento, envolvendo encontros para discussão do referencial e teórico, filmes, produção de trabalhos e divulgação de dados de pesquisas desenvolvidas pelos participantes. A seguir, apresentamos algumas dessas produções.

\section{PRODUÇÕES DESENVOLVIDAS}

A produção científica foi um dos nossos principais resultados, que disseminou as pesquisas realizadas ao longo desses dois anos de atuação do projeto, em que os alunos bolsistas desenvolveram trabalhos de diversas naturezas. A seguir, na Tabela 3, apresentamos as produções desenvolvidas no período de 2014 a 2016.

\section{TABELA 3 - PRODUÇÕES DESENVOLVIDAS PELOS BOLSISTAS DO OBEDUC/UFPI. 2013-2016.}

\begin{tabular}{|c|c|}
\hline TIPOS DE PRODUÇÕES & TÍTULOS \\
\hline \multirow{2}{*}{ DISSERTAÇÕES } & $\begin{array}{l}\text { A prática do Coordenador Pedagógico no contexto da Escola de Tempo } \\
\text { Integral: desafios da Educação Integral e Integrada. } 2015 .\end{array}$ \\
\hline & $\begin{array}{l}\text { A racionalidade pedagógica do professor de escola de tempo integral e sua } \\
\text { interface com o currículo. } 2016 .\end{array}$ \\
\hline LIVROS & $\begin{array}{l}\text { Conversas Pedagógicas: a epistemologia da escola de tempo integral. } \\
\qquad 2015 .\end{array}$ \\
\hline \multirow{4}{*}{$\begin{array}{l}\text { TRABALHOS DE } \\
\text { CONCLUSÃO DE } \\
\text { CURSO DE } \\
\text { GRADUAÇÃO }\end{array}$} & $\begin{array}{c}\text { A organização do trabalho pedagógico na escola de tempo integral: uma } \\
\text { experiência no CETI Freitas Neto. } 2014 .\end{array}$ \\
\hline & $\begin{array}{l}\text { A implantação do tempo integral no CEFTI Professor Raldir Cavalcante } \\
\text { Bastos. } 2014 .\end{array}$ \\
\hline & $\begin{array}{l}\text { A Prática do supervisor do Programa Institucional de Bolsa de Iniciação a } \\
\text { Docência no contexto da escola tempo integral. } 2015 .\end{array}$ \\
\hline & $\begin{array}{l}\text { As contribuições do coordenador pedagógico no contexto escolar: um } \\
\text { estudo na Escola Municipal Esther Couto na cidade de Teresina-PI. } 2016 .\end{array}$ \\
\hline \multirow{3}{*}{$\begin{array}{l}\text { TRABALHOS DE } \\
\text { INICIAÇÃO CIENTÍFICA } \\
\text { - PIBIC }\end{array}$} & $\begin{array}{l}\text { Os gestores da escola de tempo integral: seus saberes e suas } \\
\text { possibilidades. } 2015 .\end{array}$ \\
\hline & $\begin{array}{c}\text { A articulação da gestão escolar com os monitores do programa mais } \\
\text { educação na perspectiva da integralidade humana na escola de tempo } \\
\text { integral. } 2015 .\end{array}$ \\
\hline & $\begin{array}{c}\text { A gestão da construção dos diferentes saberes da docência no estágio } \\
\text { obrigatório dos alunos dos cursos de licenciatura na escola de tempo } \\
\text { integral. } 2016 .\end{array}$ \\
\hline $\begin{array}{l}\text { PROJETO DE } \\
\text { PESOUISA }\end{array}$ & $\begin{array}{c}\text { Projeto " Os saberes do trabalho pedagógico na escola de tempo integral: } \\
\text { um estudo sobre a epistemologia da prática escolar na educação básica". } \\
\text { Envolveu duas bolsistas de IC, com bolsa do CNPq. Portanto, comporta } \\
\text { dois planos de trabalho com olhares distintos sobre a ETI. }\end{array}$ \\
\hline
\end{tabular}




\begin{tabular}{|c|c|}
\hline CURSOS & $\begin{array}{l}\text { Introdução ao Excell 20h; } \\
\text { Primeiros Socorros. 20h; } \\
\text { Relações Interpessoais para Professores, dentre outros que contribuíram } \\
\text { para a formação de todos os participantes do observatório e do núcleo de } \\
\text { pesquisa. }\end{array}$ \\
\hline PALESTRA & $\begin{array}{c}\text { Educação integral e escola integral e integradora, com a Profa. Dra. Marta } \\
\text { Scarpato (PUC/SP). }\end{array}$ \\
\hline \multirow[b]{2}{*}{$\begin{array}{l}\text { OUTRAS } \\
\text { PRODUÇÕES }\end{array}$} & $\begin{array}{c}\text { Slides sobre a caracterização e dados das escolas Darcy Araújo e Freiras } \\
\text { Neto. }\end{array}$ \\
\hline & $\begin{array}{l}\text { Slides para apresentação de seminários sobre a educação integral/escola } \\
\text { de tempo integral/O Programa Mais Educação/ Paulo Freire/Edgar Morin. } \\
\text { Relatórios de pesquisa. }\end{array}$ \\
\hline $\begin{array}{l}\text { EVENTOS } \\
\text { CIENTÍFICOS }\end{array}$ & $\begin{array}{l}\text { I Colóquio de Pesquisa, Práticas e Aprendizagens na Educação da UFPI } \\
\text { (CPPAE), realizado em agosto de } 2014 \text {. }\end{array}$ \\
\hline
\end{tabular}

Fonte: Dados OBEDUC/UFPI, 2015.

Os trabalhos listados acimas estão publicados em livros e anais de eventos, proporcionando a divulgação dessas pesquisas no meio científico. Além disso, os participantes vinculados ao projeto também estiveram envolvidos em eventos científicos, conforme trazemos na Tabela 4.

\section{TABELA 4 - EVENTOS CIENTÍFICOS PARTICIPADOS PELOS INTEGRANTES DO OBEDUC/UFPI. 2013-2015.}

1. VII Colóquio Nacional da Afirse, realizado em Mossoró - RN (setembro de 2013). Participação no VII Colóquio Nacional da Afirse, realizado em Mossoró - RN.

\begin{tabular}{c|c}
\hline $\begin{array}{c}\text { 2. I Colóquio de Pesquisas, Aprendizagens e Práticas em Educação - I } \\
\text { CPAPE, promovido pelo NIPEEPP, no âmbito do OBEDUC/UFPI. }\end{array}$ & 2014 \\
\hline 3. III Encontro de Iniciação a Docência - ENID/UFPI. & 2014 \\
\hline $\begin{array}{c}\text { 4. VIII Colóquio Internacional de Educação e Contemporaneidade, } \\
\text { realizado em São Cristóvão-SE. }\end{array}$ & 2014 \\
\hline $\begin{array}{c}\text { 5. Organização e participação do I SIMCOP/UFPI (Simpósio dos } \\
\text { Coordenadores do Pibid da UFPI). }\end{array}$ & 2014 \\
\hline $\begin{array}{c}\text { 6. VI Encontro Inter-regional Norte, Nordeste e Centro-Oeste sobre } \\
\text { Formação Docente para a Educação Básica e Superior (ENFORSUP) }\end{array}$ & 2015 \\
\hline
\end{tabular}

Fonte: Dados OBEDUC/UFPI, 2015.

A participação nos eventos científicos também possibilitou a produção de trabalhos sob a forma de artigos e/ou resumos expandidos, nos quais listamos alguns deles na Tabela 5: 


\section{autêntica}

\section{TABELA 5 - PARTICIPAÇÃO NOS EVENTOS CIENTÍFICOS E TRABALHOS APRESENTADOS.}

\begin{tabular}{|c|c|c|}
\hline $\begin{array}{l}\text { NATUREZA DA } \\
\text { PRODUÇÃO }\end{array}$ & TÍTULO & EVENTO \\
\hline ARTIGO & $\begin{array}{c}\text { O cotidiano da escola de tempo integral: } \\
\text { discutindo concepções e experiências da práxis } \\
\text { docente. }\end{array}$ & $\begin{array}{l}\text { I seminário Internacional } \\
\text { de Educação Integral, Belo } \\
\text { Horizonte-MG. } 2014 .\end{array}$ \\
\hline \multirow[b]{2}{*}{$\begin{array}{l}\text { RESUMO } \\
\text { EXPANDIDO }\end{array}$} & $\begin{array}{l}\text { Escola de Tempo Integral: discutindo concepções } \\
\text { e experiências no cotidiano da práxis docente. }\end{array}$ & \multirow{2}{*}{$\begin{array}{l}\text { III Encontro de Iniciação a } \\
\text { Docência (ENID/UFPI). }\end{array}$} \\
\hline & $\begin{array}{c}\text { Perspectiva Histórica da Escola de Tempo } \\
\text { Integral no Brasil: um recorte temporal de } 1930 \\
\text { aos dias atuais. }\end{array}$ & \\
\hline \multirow{3}{*}{ ARTIGO } & $\begin{array}{c}\text { A utilização de jogos didáticos na visão dos } \\
\text { professores de ciências da Educação de Jovens } \\
\text { e Adultos. }\end{array}$ & $\begin{array}{l}\text { VIII Colóquio Internacional } \\
\text { de Educação e } \\
\text { Contemporaneidade, realizado } \\
\text { em São Cristóvão - SE. }\end{array}$ \\
\hline & $\begin{array}{c}\text { A educação em tempo integral: uma política que } \\
\text { visa formação multidimensional. }\end{array}$ & \multirow{2}{*}{$\begin{array}{c}\text { VII } \\
\text { Colóquio da Associação } \\
\text { Francofone Internacional } \\
\text { de Pesquisa Científica em } \\
\text { Educação - AFIRSE } \\
\text { Mossoró-RN }\end{array}$} \\
\hline & $\begin{array}{l}\text { A perspectiva de currículo na Escola de Tempo } \\
\text { Integral: reflexões preliminares. }\end{array}$ & \\
\hline \multirow{6}{*}{$\begin{array}{l}\text { RESUMO } \\
\text { EXPANDIDO }\end{array}$} & $\begin{array}{l}\text { Revisão Integrativa aplicada à educação: olhares } \\
\text { sobre a escola de tempo integral. }\end{array}$ & \multirow{6}{*}{$\begin{array}{l}\text { I Colóquio de Pesquisas, } \\
\text { Aprendizagens e Práticas em } \\
\text { Educação (CPAPE/UFPI). }\end{array}$} \\
\hline & $\begin{array}{c}\text { A importância de práticas educativas para a } \\
\text { educação ambiental: discutindo conceitos no } \\
\text { cotidiano escolar. }\end{array}$ & \\
\hline & $\begin{array}{l}\text { A perspectiva de currículo na Escola de Tempo } \\
\text { Integral: reflexões preliminares. }\end{array}$ & \\
\hline & $\begin{array}{l}\text { Um estudo sobre a organização do trabalho } \\
\text { pedagógico na Escola de Tempo Integral. }\end{array}$ & \\
\hline & $\begin{array}{c}\text { O pedagogo no contexto da escola de } \\
\text { tempo integral: novas atribuições, desafios, } \\
\text { possibilidades. }\end{array}$ & \\
\hline & $\begin{array}{c}\text { O olhar do coordenador pedagógico sobre a } \\
\text { formação continuada de professores que atuam } \\
\text { na Educação Integral em duas Escolas de Tempo } \\
\text { Integral em Teresina. }\end{array}$ & \\
\hline
\end{tabular}

Fonte: Dados das autoras, 2015. 


\section{autêntica}

Para compilar o resultado da pesquisa do OBEDUC foi produzido um livro intitulado "Conversas Pedagógicas: a epistemologia da escola de tempo integral". Porém, as contribuições não se encerram nas produções científicas ou didático-pedagógicas, elas se estendem e atingem aqueles que diretamente vivenciaram o projeto, os alunos das licenciaturas, os professores da educação básica e educação superior, bem como o técnico administrativo. Este fato pode ser observado em seus depoimentos:

A ideia do Observatório da Educação vem explicita nas suas contribuições em três principais vertentes: no âmbito pessoal dos alunos de graduação e pós graduação que compõem o grupo; no âmbito da escola; e no âmbito da universidade.[...] O OBEDUC oportunizou a seus membros experiências teórico-metodológicas, epistemológicas e de pesquisa, que veio a proporcionar a reflexão acerca da educação como um todo. Assim, entendemos que o OBEDUC/UFPI traz contribuições a nossa formação em particular, quanto as contribuições sociais que trouxe a escola e a universidade. (Participante do OBEDUC/UFPI - Mestranda em Educação)

O desenvolvimento do projeto OBEDUC me proporcionou vivências singulares, me ofereceu capacitações que não estão previstas para o meu curso de graduação, está contribuindo para uma formação mais completa. O OBEDUC me permitiu conhecer o interior das escolas que colaboram com o programa, conversar com as professoras e coordenadoras podendo traçar paralelos e perceber os distanciamentos entre a escola de tempo integral que foi pensada e a escola de tempo integral que temos implantada aqui. Enquanto professora que almejo ser, percebo que o programa me capacita e contribui para que eu dê o retorno à sociedade quando eu estiver atuando em sala de aula ou mesmo conversando sobre a educação. Percebo esse programa como via de amadurecimento profissional e pessoal, pois trabalhamos e nos desenvolvemos coletivamente. (Participante do OBEDUC/UFPI - Aluna PIBIC)

Isso significa que a participação no OBEDUC/UFPI colaborou para a formação dos bolsistas no que se refere ao desenvolvimento da atitude investigativa diante da realidade concreta que singulariza o espaço escolar, sobretudo o da escola de tempo integral. Os estudos e as discussões em grupo, bem como a observação do cotidiano escolar possibilitam a ampliação dos saberes construídos (TARDIF, 2002), a respeito dos desafios e das possibilidades que a educação integral engendra na realidade de Teresina-PI.

O projeto desenvolvido no âmbito do OBEDUC contribui para o desenvolvimento de competências e habilidades dos alunos da licenciaturas nas atividades acadêmicas e na construção de sua práxis docente. A organização de eventos como o I CPAPE, proporciona aos discentes a oportunidade de desenvolver com responsabilidade as tarefas que lhes são propostas, para tornar possível a realização dos eventos. (Participante do OBEDUC/UFPI - Mestranda em Educação)

O relato em questão representa a participação da equipe do OBEDUC/UFPI nos eventos $m$ dos eventos III ENID - Encontro de Iniciação a Docência da UFPI e I Colóquio de Pesquisa, Aprendizagens e Práticas em Educação (I CPAPE/UFPI), destacando as contribuições do projeto para o aprimoramento dos cursos de licenciatura, ao tempo que proporcionou o conhecimento do referencial teórico básico, que preconizam as ações da epistemologia da prática educativa na escola.

As escolas de forma direta e indireta puderam usufruir das ações do OBEDUC, seja ao vivenciarem o desenvolvimento de atividades que incentivaram a curiosidade e o prazer do aprendizado, ou promoveram a formação continuada dos professores, com reflexões sobre a educação e as perspectivas da educação integral, que proporcionam melhoria à aprendizagem dos alunos. Os relatos das coordenadoras pedagógicas 


\section{autêntica}

das duas escolas conveniadas, e que também são integrantes do NIPEEPP/UFPI afirmam a importância do Observatório da Educação.

O Projeto proporcionou vários estudos, reflexões e seminários através dos estudos realizados de vários autores como: Anísio Teixeira, Dewey, Antonio Carlos Gil, Edgar Morim, Gademer, Haberms, Paulo Freire, Tardiff, Antonio Novoa, Herry Giroux entre outros. [...] mostrou que a escola de tempo integral quando inserida num contexto de relações, considera o sujeito em estudo em várias dimensões como: física, cognitiva, intelectual, afetiva, social e ético, tendo em vista o desenvolvimento pleno e voltado para a cidadania. (Coordenadora Pedagógica do CETI Darcy Araújo)

Participar deste projeto Obeduc é uma experiência impar que só nos proporciona crescimento intelectual. As pesquisas realizadas, os textos lidos, os autores estudados muito enriquecem nossos conhecimentos, contribuem para o desenvolvimento dos nossos trabalhos em relação às escolas. (Coordenadora Pedagógica CETI Freitas Neto)

Segundo Costa (2015), o Coordenador Pedagógico (CP) é um profissional que desempenha um importante papel na Escola de Tempo Integral, pois tem o papel de mediador dos processos de ensino e aprendizagem. Além disso, o CP é um ator de grande importância no cenário escolar, pois tem o papel primordial de desenvolver, junto aos professores e alunos, o processo de ensino e aprendizagem. Assim, a participação no projeto proporcionou uma formação continuada às duas coordenadoras envolvidas, contribuindo para uma reflexão da sua prática pedagógica. 


\section{autêntica}

\section{CONSIDERAÇÕES FINAIS}

Desenvolver a pesquisa inovadora submetida ao OBEDUC no âmbito do NIPEEPP/PPGED/UFPI significou dinamizar as ações voltadas à formação de pesquisadores e de professores no âmbito da UFPI, pois oportunizou aos estudantes da graduação e da pós-graduação a participação em experiências teórico-metodológicas e práticas de pesquisa no lócus escolar, o que favorece sua inserção na escola pública. Significou, também, promover o desenvolvimento profissional dos participantes, perceptível na ampliação da produção bibliográfica e participação em eventos da área.

Portanto, a realização deste projeto por um lado fomentou a produção acadêmica sobre a escola de tempo integral, articulando a interação entre a pós-graduação, as licenciaturas e as escolas da rede pública de educação básica. Esta articulação decorreu do envolvimento da equipe da pesquisa composta por professores e alunos do PPGEd/UFPI, professores da educação básica e alunos e professores de cursos de licenciatura. Por outro lado, auxiliou na implantação de ações de formação continuada de professores da educação básica, considerando a parceria estabelecida entre a escola e a universidade.

Em tempos que se discute a formação do professor para o ensino e para a pesquisa, não dissociando um do outro como alerta Freire (1996), este projeto foi significativamente importante para formação docente no âmbito da UFPI. Neste sentido, o financiamento da Capes foi de grande relevância para a melhoria do nosso Programa de Pós-Graduação e para consolidação do nosso Núcleo de Pesquisa (NIPEEPP) que antes mal sobrevivia diante das dificuldades decorrentes da escassez de recursos para a divulgação dos nossos trabalhos.

Nossa experiência e resultados mostram os impactos relevantes do OBEDUC para a educação e, principalmente, para a formação de professores. Por esta razão seria interessante que a CAPES o ampliasse, seja em forma de projetos individuais ou em rede. Assim, sugerimos que o número de bolsas, de modo geral, fosse ampliado, incluindo neste grupo os diretores das escolas e que cada projeto possibilitasse a existência de dois coordenadores (institucional e processo de pesquisa), para os quais fosse admitida uma bolsa. Também sugerimos que o OBEDUC seja um continuum, a exemplo de outros Programas, ou seja, a cada ano o coordenador, garantiria a manutenção de sua bancada de pesquisa, podendo ampliar, ajustar ou propor nova pesquisa, desde que prestasse contas financeira e academicamente dos resultados.

Para finalizar, destacamos que todos objetivos propostos pelo projeto OBEDUC, são valorosos. Mas, provavelmente o objetivo mais relevante que destacamos para o OBEDUC/UFPI/NIPEEPP foi o de proporcionar aos bolsistas participação em experiências metodológicas e práticas de pesquisa, articuladas com a realidade local da escola, isto é, proporcionar uma formação fundamentada na pesquisa, na prática, na reflexão das prática; uma formação mais sólida, mais crítica e mais reflexiva, fundada no compromisso, na autonomia e emancipação do sujeito, sendo que alguns deles já professores em exercício da educação básica ou da educação superior, inclusive da UFPI. 


\section{autêntica}

\section{REFERÊNCIAS}

ALARCÃO, Isabel. Professores reflexivos em uma escola reflexiva. 7. ed. Coleção Questões da nossa época. v.8. São Paulo: Cortez, 2010.

AMARAL, Elaine Abrahão. Escola em tempo integral: espaço de construção ou de precarização do processo educacional? 2013. Disponível em: <www.funedi.edu.br/revista/files/numero3/n3\%201semestre2012/7edu cacaoemtempointegral.pdf>. Acesso em: 15 ago. 2016.

ANDRÉ, Marli Eliza D. A de. Etnografia da prática escolar. 2. ed. Campinas-SP: Papirus, 1995.

ARROYO, Miguel Gonzales. O direito ao tempo de escola. Cadernos de Pesquisa, s.l., v.01, n. 65, p. 3-10, maio. 1988.

BRASIL. Manual Operacional de Educação Integral. Brasília/DF, 2014. Disponível em: <http://portal.mec.gov. br/index.php?option=com_docman\&view=download\&alias=15842-manual-operacional-de-educacao-integral-2014\&category_slug=junho-2014-pdf\&Itemid=30192 >. Acesso em: 25 set. 2016.

Portaria normativa Interministerial n 17, de 24 de abril de 2007. Institui o Programa Mais Educação, que visa fomentar a educação integral de crianças, adolescentes e jovens, por meio do apoio a atividades socioeducativas no contraturno escolar. Disponível em: <http://portal.mec.gov.br/arquivos/pdf/mais_educacao.pdf>. Acesso em: 25 set. 2016.

Instituto Nacional de Estudos e Pesquisas Educacionais Anísio Teixeira - INEP. Relatório Problematização da Qualidade na Pesquisa: levantamento do custo-aluno ano em escola de educação básica que oferecem condições para oferta de um ensino de qualidade. Brasília: INEP, 2004.

Lei no 9.394, de 20 de dezembro de 1996. Dispõe sobre as Diretrizes e Bases da Educação Nacional. Diário Oficial da União, Brasília, DF, 23 dez. 1996. Disponível em: < http://www.planalto.gov.br/ ccivil_03/leis/L9394.htm>. Acesso em: 25 set. 2016.

DEWEY, John. Vida e educação. Tradução Anísio S. Teixeira. 10. ed. São Paulo: Melhoramentos, 2002.

CAVALIERE, Ana Maria Villela. Educação integral: uma nova identidade para a escola brasileira? Revista Educação e Sociedade, Campinas, v. 23, n. 81, p. 247-270, dez. 2002.

COSTA, Antonia Flávia Moraes da. A prática do coordenador pedagógico no contexto da Escola de Tempo Integral: desafios da educação integrada. 2015. 113 f. Dissertação (Mestrado em Educação) - Universidade Federal do Piauí, Teresina, 2015.

COULON, Alain. Etnometodologia. Tradução Epharim Ferreira Alves. Petrópolis-RJ: Vozes, 1995.

DELORS, Jackes. Educação: um tesouro a descobrir: relatório para a UNESCO da Comissão Internacional sobre Educação para todos. 6. ed. São Paulo: Cortez; 2001.

DOURADO, Anne Caroline Soares. A racionalidade pedagógica do professor de escola de tempo integral e sua interface com o currículo. 2016. 107f. Dissertação (Mestrado em Educação) - Programa de Pós-Graduação em Educação, Universidade Federal do Piauí, Teresina, 2016. 
FREIRE, Paulo. Pedagogia da autonomia: saberes necessários à prática educativa. São Paulo: Paz e Terra, 1996.

GADOTTI, Moacir. Educação integral no Brasil: inovações em processo. São Paulo: Instituto Paulo Freire, 2009.

GONÇALVES, Antonio Sérgio. Reflexões sobre educação integral e escola de tempo integral. Cadernos Cenpec, n. 2, Educação Integral, jul-dez. 2006.

HABERMAS, Jürgen. Racionalidade e comunicação. Tradução Paulo Rodrigues. Lisboa: 70/Biblioteca de Filosofia Contemporânea, 2002.

MOREIRA, Herivelto; CALEFFE, Luiz Gonzaga. Metodologia da pesquisa para o professor pesquisador. 2. ed. Rio de janeiro: Lamparina, 2008.

MORIN, Edgar. Os sete saberes necessários à educação do futuro. Tradução de Catarina Eleonora F. da Silva e Jeanne Sawaya. 12. ed. São Paulo: Cortez, 2007.

NOVOA, Antonio (Coord). As organizações escolares em análise. Lisboa: Dom Quixote, 1999.

SCHÖN, Donald. A. Educando o profissional reflexivo: um novo design para o ensino e a aprendizagem. Tradução Roberto Cataldo Costa. São Paulo: Artes Médicas, 2000.

TARDIF, Maurice. Saberes docentes e formação profissional. São Paulo: Vozes, 2002.

TEIXEIRA, Anísio. Educação para a democracia. Rio de Janeiro, Editora UFRJ, 1997.

Educação não é privilégio. Rio de Janeiro: Editora UFRJ, 1994. 
